\title{
Study on Greenhouse Gases Emissions from Two Common Cars in Iran (Paykan Pick-up and Pride)
}

\author{
Ahmad Jahanbakhshi ${ }^{1, *}$, Goodarz Rezaei ${ }^{2}$ \\ ${ }^{1}$ Department of Mechanical Engineering of Biosystems, Mohaghegh Ardabili University, Ardabil, Iran \\ ${ }^{2}$ Department of Mechanical Engineering of Biosystems, Ilam University, Ilam, Iran
}

Email address:

ahmad.jahanbakhshi67@gmail.com (A. Jahanbakhshi)

${ }^{*}$ Corresponding author

\section{To cite this article:}

Ahmad Jahanbakhshi, Goodarz Rezaei. Study on Greenhouse Gases Emissions from Two Common Cars in Iran (Paykan Pick-up and Pride). International Journal of Mechanical Engineering and Applications. Vol. 5, No. 6, 2017, pp. 287-290. doi: 10.11648/j.ijmea.20170506.11

Received: October 9, 2017; Accepted: November 1, 2017; Published: December 15, 2017

\begin{abstract}
In today's world, environmental issues such as emissions from cars must be raised at an international level. The pollution which emits motor vehicles in the form of smoke and spreads in the air in a poisonous and dangerous manner is harmful for human health and the environment. This makes us study the issue and provide solutions in this regard more seriously than ever before. In this study, the amount of the emitted gases $\left(\mathrm{O}_{2}, \mathrm{CO}, \mathrm{CO}_{2}\right.$ and $\left.\mathrm{HC}\right)$ from two types of cars, namely paykan pick-up and pride was analyzed using a smoke analyzer device while the cars were in the stop mode (they were in neutral). The results show that the average concentration of $\mathrm{CO}$ and $\mathrm{HC}$ of cars exhaust is lower than the standard technical inspection of the cars which is equal to 2.5 Volume percent and $250 \mathrm{ppm}$, so both vehicles in term of the production of these two pollutants are in good condition. Also, it seems necessary to observe new standards and regulations seriously in order to control pollutants that emit all gasoline cars.
\end{abstract}

Keywords: Petrol Engine, Air Pollutants, Environment

\section{Introduction}

Nowadays, air pollution as one of the life threats on earth is of utmost importance to researchers and scholars in the fields of environmental studies and urban development. Researchers have found a significant relationship between the rate of air pollution and cardiovascular as well as respiratory diseases. reported in a study that air pollution might cause lung cancer [1].

Of the most important issues that have preoccupied the minds of the people in the world are the problems of air pollution and sharp decline of fossil fuel resources. Vehicles, especially the ones equipped with gasoline and diesel internal combustion engines are one of the most important factors that pollute the air [2]. Pollutants which are emitted from cars increase the threat of respiratory death, affect the performance of the lungs, exacerbate asthma and cause other respiratory symptoms such as cough, bronchitis, cardiovascular diseases, etc. They also increase the infection rate for other respiratory diseases [3 and 4]. According to the studies carried out so far, more than $72 \%$ of the pollution in metropolitans is due to the traffic (vehicles travelling) in the cities. Therefore, considering the major role of transportation in the creation of pollution in metropolitans, using public means of transportation seems to be necessary [5]. Gasoline vehicles emit four major pollutants: carbon monoxide, nitrogen oxides, hydrocarbons and particles. Means of transportation have been recognized as the most effective factor for environmental degradation and health hazards for urban residents. Primary harmful effects of air pollution are generally caused by the relatively low concentrations of different types of poisonous materials in urban air over long periods. When air flow is confined at a low atmospheric level and there is temperature inversion, the concentration of pollutants would increase in the atmosphere and this might lead to an environmental disaster. Temperature inversion or atmospheric inversion occurs when warm air masses are above a mass of relatively cold air. When the air becomes still as a result of this phenomenon, the gases that pollute urban air are not evacuated due to the ascending currents of the atmosphere. Constant emission of poisonous gases from 
cars, factories and houses, heavily pollutes the air in cities [6]. A car's exhaust pipe emits a number of poisonous gases in the atmosphere. Three types of gases which concern us most are Hydrocarbons (HC), Carbon Monoxide (CO) and Nitrogen Oxides. These pollutants have been directly or indirectly related to acid rain, smog and carbon monoxide poisoning. Their amount has also increased in the low-level concentrations of the ozone layer. Exhaust emissions depend on the mixture of gasoline and air in the engine of a gasoline vehicle. More than 90 percent of the carbon monoxide that exists in cities and around 30 to 40 percent of nitrogen oxides in urban environments is emitted through exhaust pipes of the cars [7].

Human body needs almost $22 \mathrm{Kg}$ of air every day so that it can get the required amount of oxygen. It is necessary that in this interaction, pure air gets into one's body. Therefore, preventing air pollution is an absolutely essential task. The aim of this study is to measure the amount of pollutants emitted from two types of cars, namely paykan pick-up and pride in the city of Islamabad-e-Gharb in Iran and investigate their effect on human health. The rate of pollutants is also compared to the existing standards.

\section{Materials and Methods}

This study is a descriptive and cross-sectional piece of research that was conducted in the year 2016. To carry out the tests, two cars (paykan pick-up and pride) which had been manufactured in 2014 were used. Samples were taken while the cars were stable and their engines were running. Before doing the tests, the cars' engines had been running so that the motor temperature reached the optimum point [8]. This was done since the performance and conditions of emissions are different in cold and warm engines. The gases $\left(\mathrm{O}_{2}, \mathrm{CO}, \mathrm{CO}_{2}\right.$ and $\left.\mathrm{HC}\right)$ that were emitted through the exhaust pipes were measured using the ULTIMA 400; a device made in France whose picture is shown in Figure 1. To conduct the measurement, the head end of the sensor (the sucker) was placed inside the cars' exhaust pipes (Figure 1). Each of the tests was repeated six times for each car and at the end the resulting data were analyzed through Excel 2013 and compared to the existing standard (Table 1).

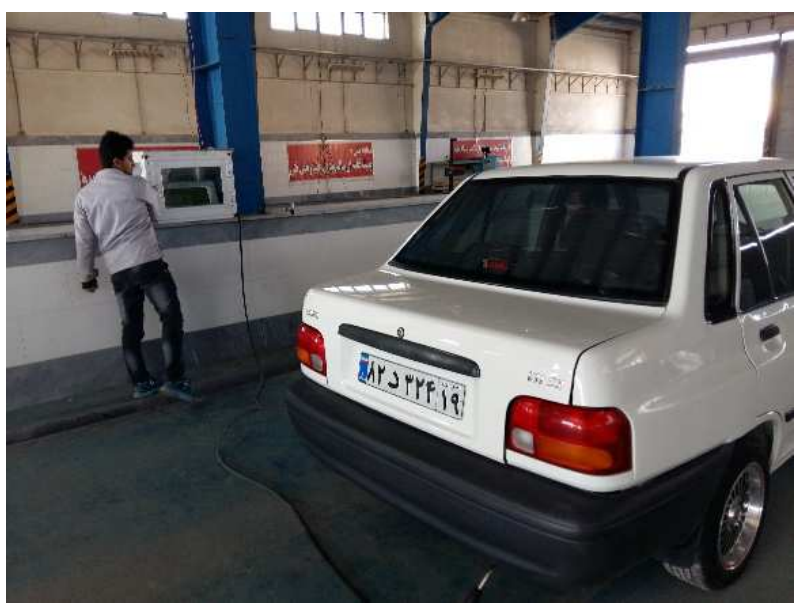

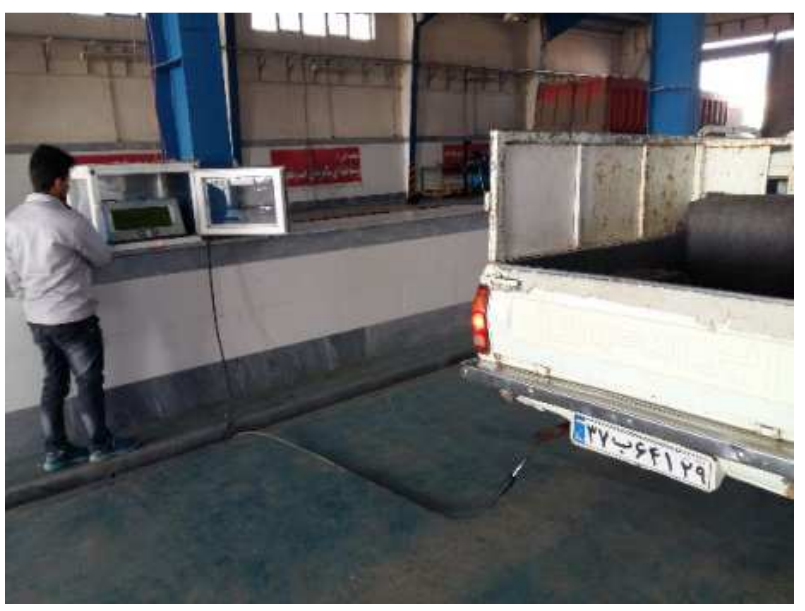

Figure 1. Measurement of the emissions from the exhaust pipes of the cars under study.

Table 1. Standard emissions from the exhaust pipes in injector engines [8].

\begin{tabular}{llll}
\hline $\mathbf{O}_{2}$ & $\mathbf{C O}$ & $\mathbf{C O}_{2}$ & HC \\
\hline Less than 3\% & Less than 2.5\% & More than 14\% & Less than 250 ppm \\
\hline
\end{tabular}

\section{Results and Discussion}

The comparison between the mean concentrations of the gases that are emitted through the cars' exhaust pipes with the standards is shown in Figure (2).

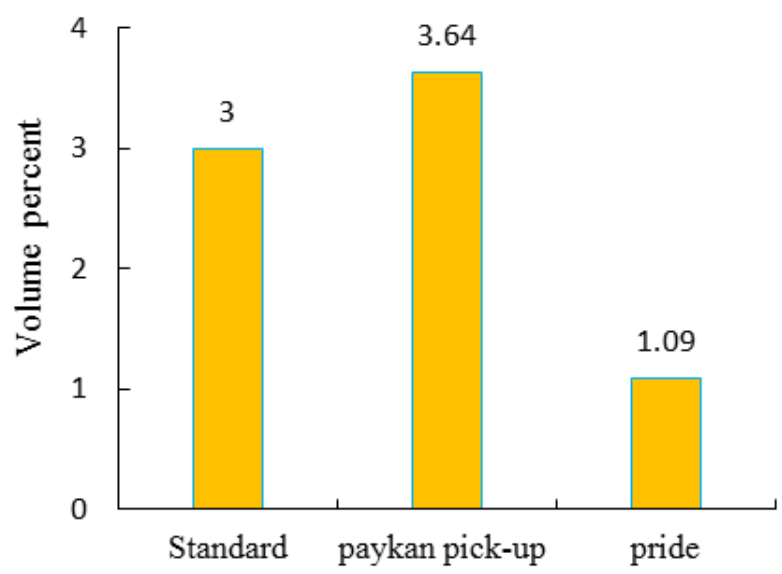

(A)

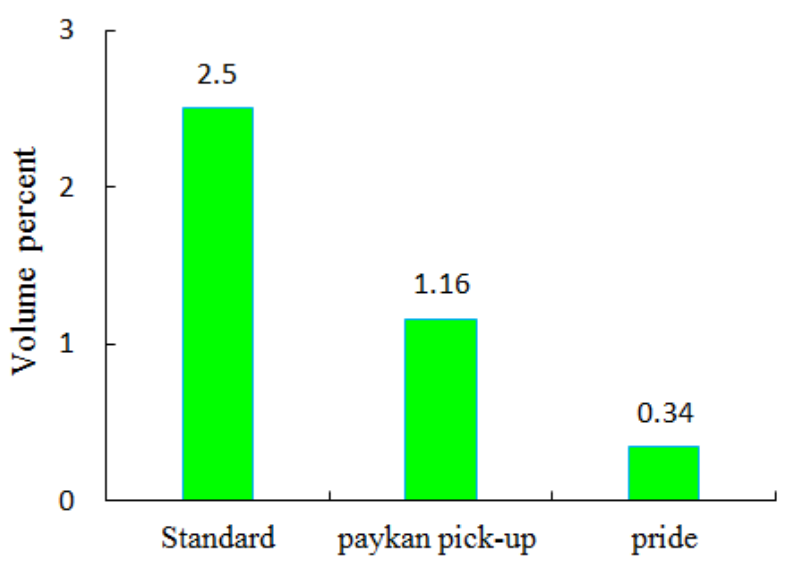

(B) 


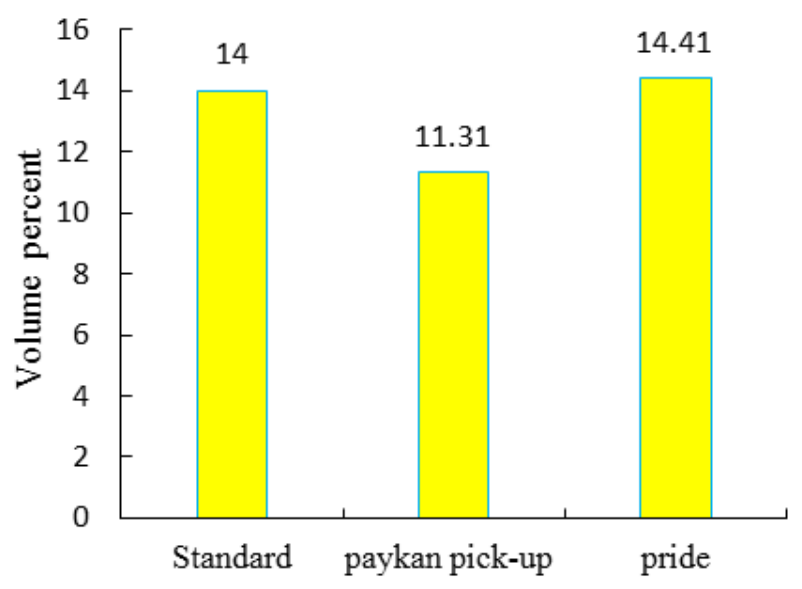

(C)

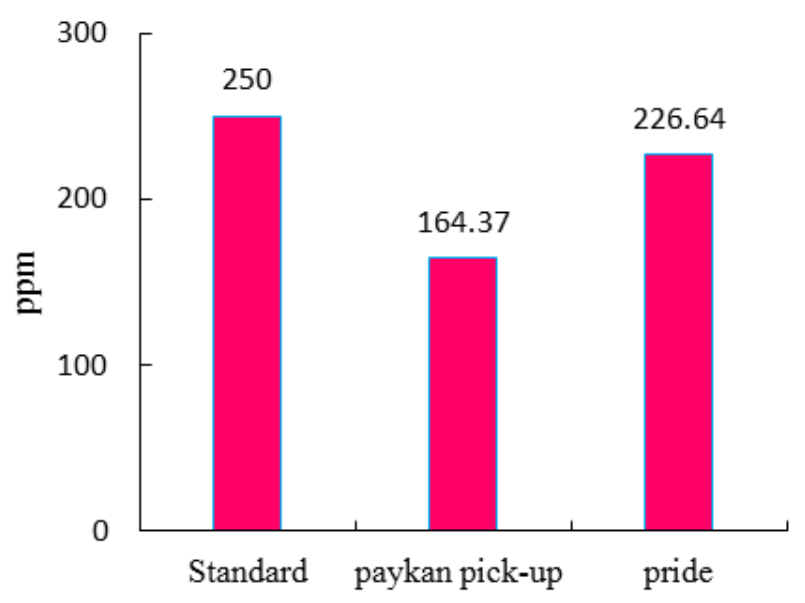

(D)

Figure 2. Comparison between the concentrations of the gases emitted from the cars under study and the existing standards. A) $\mathrm{O}_{2}, \mathrm{~B}$ ) $\left.\mathrm{CO}, \mathrm{C}\right) \mathrm{CO}_{2}$ and D) $H C$.

\subsection{Oxygen $\left(\mathrm{O}_{2}\right)$}

Volume percent for the concentration of the $\mathrm{O}_{2}$ gas that is emitted from the cars' exhaust pipes is compared to the standard in Figure 2 (a). In standard temperature and pressure, oxygen exists in gas form and consists of two oxygen atoms with the chemical formula of $\mathrm{O}_{2}$. Oxygen is one of the major elements in the air and is produced through photosynthesis in plants. It is a necessary element for the act of breathing in living beings. The results of the study indicate that the amount of oxygen produced in a Pride is lower than the standard while the rate of oxygen produced by a Paykan pick-up is higher than the standard. It must be noted that we can ignore this element $\left(\mathrm{O}_{2}\right)$ sincerity does not pose any risks to the living beings.

\subsection{Carbon Monoxide (CO)}

Mean volume percent of the pollutant concentration (CO) emitted from the cars' exhaust pipes was compared to the standard as shown in Figure 2 (b). As can be seen, in both cars (Paykan pick-up and Pride), the average volume percent for the $\mathrm{CO}$ gas is lower than the standard. It must be mentioned that carbon monoxide is produced in the engine when the combustible combine of the fuel and air is rich but there is not sufficient oxygen for the combustion cycle. When there is not sufficient oxygen to turn all the carbon into $\mathrm{CO}_{2}$, some of the fuel is not burned and some of the carbon remains in the form of $\mathrm{CO}$. This gas is flammable and burns with a blue flame. These results are consistent with those reported in Haagen-Smit [9].

\subsection{Carbon Dioxide $\left(\mathrm{CO}_{2}\right)$}

The comparison between the volume percent of the $\mathrm{CO}_{2}$ emitted from the cars' exhaust pipes and the standard is reported in Figure 2 (C). The results show that the rate of carbon dioxide emitted from a Paykan pick-up is less than the standard while the amount of $\mathrm{CO}_{2}$ produced by a Pride is above the standard. This can be due to full combustion in the motor of a Pride. Carbon dioxide is colorless and odorless and has harmful effects on the environment. Moreover, it causes calcium to deposit in body tissues and reduces cardiac contractility. Excessive increase in the amount of carbon dioxide contributes to the issue of greenhouse gases and global warming crisis. These results are consistent with the results obtained by Davidson [10], Baumgarten [11] and Lancet [4].

\subsection{Unburned Hydrocarbons (HC)}

The comparison between the concentrations of the HC that is emitted from the cars' exhaust pipes with the standard is shown in Figure 2 (d). The results indicate that in both vehicles (Paykan pick-up and Pride), the average amount of the $\mathrm{HC}$ pollutant is below the standard. It should also be noted that numerous factors contribute to the production of hydrocarbons the most important of which are: the ratio of the air to non-stoichiometric fuel, incomplete combustion, volumes related to joints and fractures, leakage through the exhaust valve, simultaneous opening of the valves and deposits and oil on the walls of the combustion chamber. It is suggested that the above-mentioned factors be technically reviewed in a Pride since the rate of unburned hydrocarbons in this car is higher than that of the Paykan pick-up. In the similar studies, researchers reported Emissions of unburned hydrocarbons ( $\mathrm{HC})$ and carbon monoxide (CO) to increase with engine deposit formation [12-16].

According to the studies carried out, it can generally be stated that when the pressure of the carbon dioxide gas is increases, very severe and dangerous changes happen in the breathing pattern. In addition, when the pressure of the oxygen gas decreases, very drastic and hazardous changes occur in breathing. Therefore, if for any reason the pressure of the carbon dioxide gas increases in the environment or there would be a decrease in the pressure of oxygen, serious respiratory problems including suffocation and death might take place.

One of the methods that can be applied to reduce the danger of the smoke emitted through the exhaust pipes is to use catalytic converters. As a matter of fact, a catalyst 
encourages chemical interaction among substances that are combined with each other or separated from one another. It is possible to reduce the production of pollutants through improving the quality of the fuel, having an optimal design for the combustion system or re-burning the gases produced in combustion. To prevent emission of pollutants in the environment, refining systems for exhaust gases could be installed. Applying methods that reduce the rate of pollutant production is very costly. Therefore, using such methods is not cost-effective today in Iran. So, in present conditions, refining the gases that are emitted through exhaust pipes of the cars can be suggested as a quick and cheap solution. Besides that, using solid Nano particles in fuels makes the fuelpermeate more into the compressed air in the process of fuel injection. This way the air-fuel mixture is improved and thus the combustion is more complete which in turn leads to higher brake power and workflow efficiency.

\section{Conclusion}

Having carefully studied the information obtained through this piece of research, we can conclude that in order to prevent air pollution, environmental pollution and control the rate of pollutants, new international standards should be observed. Moreover, application of the suggested solutions as well as the observance of the standards can be considered as an effective step in reducing fuel consumption and the pollutants that are emitted through cars' exhaust pipes and thus extending the life of the vehicle.

\section{References}

[1] Barbone, F., Bovenzi, M., Cavallieri, F., Stanta, G., 1995. Air pollution and lung cancer in Trieste, Italy. American Journal of Epidemiology, 141 (12), 1161-1169.

[2] Dargahi, A., golestanifar, H., Alavi. S., 2012. Evaluation of emitted pollutants from automobile exhaust in Kermanshah and its impact on human health. $2^{\text {th }}$ National Conference OF hygiene, Safety and Environment, Islamic Azad University, Mahshahr, Iran. (In Persian).

[3] Sun, H. L., Chou, M. C., Lue. K. H., 2006. The relationship of air pollution to ED visits for asthma differ between children and adults. The American journal of emergency medicine, 24 (6), 709-713.

[4] Lancet, T., 2006. WHO's global air-quality guidelines. The Lancet, 368 (9544), 1302.

[5] Ghyasaddin, M., 2006. air pollution. Tehran University Publications. (In Persian).

[6] Chambers, L. A., 2013. Classification and extent of air pollution problems. Air Pollution Volume I. Academic Press. New York.

[7] Bayat, R., 2005. Source Apportionment of Tehran's Air Pollution. M. Sc Thesis In Environmental Engineering, Sharif University of Technology, Tehran, Iran. (In Persian).

[8] Shaeri, A. M., Rahmati, A. R., 2012. Humans environmental Laws, regulations griteria and standards. Environmental Protection Organization, p 189. (In Persian).

[9] Haagen-Smit, A. J., 1966. Carbon monoxide levels in city driving. Archives of Environmental Health: An International Journal, 12 (5), 548-551.

[10] Davidson, C., 2003. Marine Notice: Carbon Dioxide: Health Hazard. Australian Maritime Safety Authority, 7.

[11] Baumgarten, C., 2006. Mixture formation in internal combustion engines. Springer Science \& Business Media.

[12] Zand, A. D., Mikaeili, A., Pezeshk. H., 2007. The influence of deposit control additives on exhaust $\mathrm{CO}$ and $\mathrm{HC}$ emissions from gasoline engines (case study: Tehran). Transportation Research Part D: Transport and Environment, 12 (3), 189-194.

[13] Caceres, D., Reisel, J. R., Sklyarov, A., Poehlman. A., 2003. Exhaust emission deterioration and combustion chamber deposit composition over the life cycle of small utility engines. Journal of Engineering for Gas turbines and power, $125(1), 358-364$

[14] Zerda, T. W., Yuan, X., Moore. S. M., 2001. Effects of fuel additives on the microstructure of combustion engine deposits. Carbon, 39 (10), 1589-1597.

[15] BowerJr, S. L., Litzinger, T. A., 1993. The effect of fuel composition and engine deposits on emissions from a spark ignition engine. SAE Technical Paper.

[16] Heywood, J. B., 1988. Internal combustion engine fundamentals (Vol. 930). New York: Mcgraw-hill. 